\title{
Investigatory behavior in snakes, II: Cage cleaning and the induction of defecation in snakes
}

\author{
DAVID CHISZAR, SANTFORD WELLBORN, MARY ANN WAND, \\ KENT M. SCUDDER, and HOBART M. SMITH \\ University of Colorado, Boulder, Colorado 80309
}

\begin{abstract}
In Experiment 1, boid and colubrid snakes defecated with shorter latencies after their home cages were cleaned than did control snakes that received equivalent handling without cage cleaning. Experiment 2 replicated this finding and also showed that snakes exposed to clean cages emit more tongue flicks after reintroduction to the clean home cage than do control snakes. Experiment 3 demonstrated that cage cleaning has similar effects in two species of crotalid snakes. The increase in tongue flicking after cage cleaning is interpreted as investigatory behavior and reflects the fact that snakes respond to the absence of familiar odors Experiment 4 showed that a clean cage containing odors derived from snake feces produces less tone-flick exploration and fewer defecation responses in rattlesnakes than does a clean cage without such odors.
\end{abstract}

Previous research from this laboratory has shown that snakes of several species emit greater rates of tongue flicking when placed into a novel environment than can be attributed to the handling and disturbance that attended transfer to the test situation (Chiszar, Carter, Knight, Simonsen, \& Taylor, 1976; Chiszar, Scudder, \& Knight, 1976; Chiszar, Scudder, Knight, \& Smith, 1978). This difference was taken to be an operational definition of investigatory behavior in snakes (see also Cowles \& Phelan, 1958; Glickman \& Sroges, 1966). Additional research has examined the extent to which investigatory behavior can be modified by variables such as food deprivation and/or food odors (Chiszar, Lipetz, Scudder, \& Pasanello, in press; see also Burghardt, 1967, 1969, 1970, 1975), predator odors (Chiszar, Scudder, Knight, \& Smith, 1978), and visual cues arising from potential prey (Chiszar, Radcliffe, \& Scudder, 1977; Chiszar, Radcliffe, \& Smith, 1978). Almost all of these experiments involved placing the snakes in a novel test environment in which experimental cues were introduced. In several studies, however, tests were conducted by introducing the cues to the snakes' home cages and recording tongue flicks emitted thereafter (Chiszar \& Simonsen, 1976; Taylor, 1976). In the course of the latter experiments, it was noticed by Goldberg (Note 1) that high rates of tongue flicking were seen after home cages were cleaned prepa-

Financial support for this research was provided by the M. M. Schmidt Foundation. The authors thank Janet Goldberg for technical assistance. Reprints may be obtained from D. Chiszar, Department of Psychology, University of Colorado, Boulder, Colorado 80309. ratory to test trials. Goldberg pursued this observation by comparing tongue-flick rates in two groups of snakes (Crotalus viridis). The experimental snakes were removed from their home cages and placed into holding pens while the home cages were cleaned. These snakes were then placed back into their cleaned home cages. The control snakes were removed from their home cages and placed into holding pens for the same length of time as required to clean the cages of the experimental snakes. The control snakes were then placed back into uncleaned home cages. Following these treatments, tongue flicks were recorded for all subjects for $15 \mathrm{~min}$. The experimental group emitted a far higher number of tongue flicks than the controls, indicating that the former animals had detected the change in the chemical properties of the home cage. This finding is yet another example of investigatory behavior.

Of greater interest, however, was an additional finding that all experimental subjects defecated in their cleaned home cages within several hours, whereas none of the controls did. It has been a common observation among those engaged in animal husbandry that many captive reptiles, birds, and mammals quickly soil clean home cages (Fox, 1968; Hediger, 1968; Chiszar, Wellborn, \& Wand, Note 2). It has typically been assumed that such behavior is induced by the stress of handling and disturbance that accompanies cage cleaning. Goldberg's (Note 1) experiment controlled these latter factors and therefore permitted the inference that removal of familiar odors during cleaning was a causative factor. The present experiments were designed to replicate and extend Goldberg's pilot results. 


\section{EXPERIMENT 1}

\begin{abstract}
Method
Subjects and Maintenance conditions. A mixed assemblage of boid and colubrid snakes served as subjects in five replications of Goldberg's (Note 1) study. Species (and number of individuals) included in this sample were Thamnophis sirtilis (4), Elaphe guttata (4), E. subocularis (2), Lampropeltis triangulum (2), Pituophis melanoleucus (1), Drymobias margaritiferus (1), Corallus hortulana (2), and Python reticulatus (1). All individuals were at least 3 years old, experimentally naive, and maintained singly in glass cages $\left(50 \times 27.5 \times 30 \mathrm{~cm}\right.$, at $\left.26^{\circ} \pm 2^{\circ} \mathrm{C}\right)$ containing a glass water vessel and paper floor covering. All animals were well adjusted to captivity and had been accepting food (in their home cages) on a weekly schedule for at least 6 months prior to the study. Observations were made on the day before feeding; hence, subjects were always under 6 days of food deprivation at the time data were gathered. Lights were on between 0600 and $2200 \mathrm{~h}$; observations were made between 1800 and $2200 \mathrm{~h}$.

Apparatus and Procedure. For each replication of Experiment 1, 10 individuals were selected randomly from the above sample and divided randomly into two groups $(n=5)$. The experimental and control groups were treated exactly as those in Goldberg's (Note 1) study. Cage cleaning involved washing all glass surfaces with warm water (no detergent) and replacing the paper floor covering. The dependent variable in all replications was latency to defecate (in minutes). If a snake did not defecate within $3 \mathrm{~h}$, a score of $180 \mathrm{~min}$ was assigned. Five replications were conducted over five successive weeks. A different random selection of 10 snakes was made from the subject pool for each replication.
\end{abstract}

\section{Results and Discussion}

The mean latencies for each group in each replication are shown in Figure 1; the lower right panel presents means pooled across replications. In all cases, the mean latency to defecate was lower for the
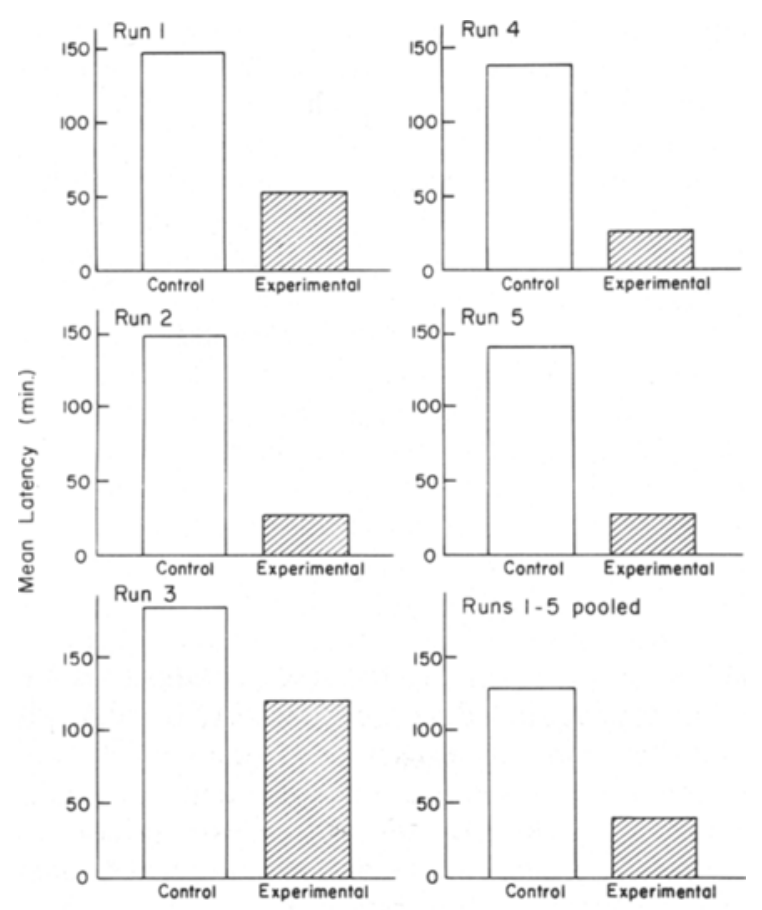

Figure 1. Mean latencies to defecate under experimental and control conditions of Experiment 1. Five replications, are shown separately and pooled. experimental group than for the control group [ts(8) $=1.93,3.17, .86,2.26$, and 2.80 for Replications $1-5$, respectively; one-tail $t_{.05}=1.86$; heterogeneity of variance, produced by assigning scores of 180 to snakes that did not defecate, was handled by using the $t$ formula recommended by Cochran \& Cox, 1950].

If latency data only from snakes that defecated are analyzed, then the control and experimental groups did not differ (means calculated across replications: $\overline{\mathrm{X}}_{\mathrm{C}}=15, \overline{\mathrm{X}}_{\mathrm{E}}=23$; one-tail $\mathrm{t}$ tests for each replication gave ps $>.05$ ). Accordingly, the latency differences reported above depend upon inclusion of nondefecating control animals, implying that within the temporal parameters of this study, defecation was a relatively rapid response or a not-at-all one for each individual. When "percent positive responses" (i.e., percent of all snakes that defecated within $180 \mathrm{~min}$ after being placed back into their home cages) was calculated across the five replications, a large difference emerged between the experimental and control groups, $82 \%$ vs. $19 \%$, respectively. Accordingly, we conclude that cage cleaning induced a greater frequency of defecations than can be accounted for by handling and disturbance.

\section{EXPERIMENT 2}

\section{Method}

Two more replications of the above procedure were conducted with the addition of a second dependent variable. During the first $20 \mathrm{~min}$ following reintroduction of experimental and control snakes to their respective home cages, all tongue flicks were recorded with the aid of hand-held counters. Snakes were again selected randomly from the subject pool. Replication 6 had three snakes in each condition; Replication 7 had four snakes in each condition. All other aspects of maintenance and procedure were identical to those described in Experiment 1.

\section{Results and Discussion}

Mean latencies for control and experimental snakes are shown in Figure 2. Panels A and B show results for Replications 6 and 7, respectively. Separate $t$ tests for latency data in Replications 6 and 7 gave values of 1.51 and 2.55 , respectively [dfs $=4$ and 6 ; one-tail $\mathrm{t}_{05}=2.13$ and 1.94]. Percent positive responses calculated across replications were $100 \%$ and $24 \%$ for experimental and control groups, respectively.

A far greater amount of tongue flicking occurred in the experimental snakes in both replications (Figure 3). These data were analyzed by mixed ANOVA with groups treated as a between-subjects factor and successive minutes treated as a within-subject factor. Separate ANOVAs for Replications 6 and 7 gave significant group main effects $(F=436.01$ and 452.69 , respectively; $\mathrm{dfs}=1 / 4$ and $1 / 6 ; \mathrm{ps}<.01$ ). The tongue flick data again indicate that a clean cage has effects that transcend handling and disturbance. Since no detergents were used in the cleaning process, experimental snakes must have been responding to the absence of familiar odors rather than to the presence of new and/or noxious chemicals. 

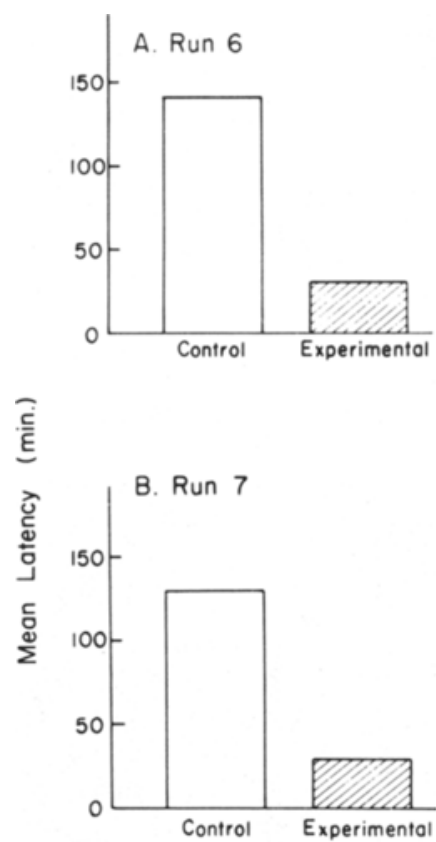

Figure 2. Mean latencies to defecate under experimental and control conditions in the two replications (Runs 6 and 7 ) of Experiment 2.

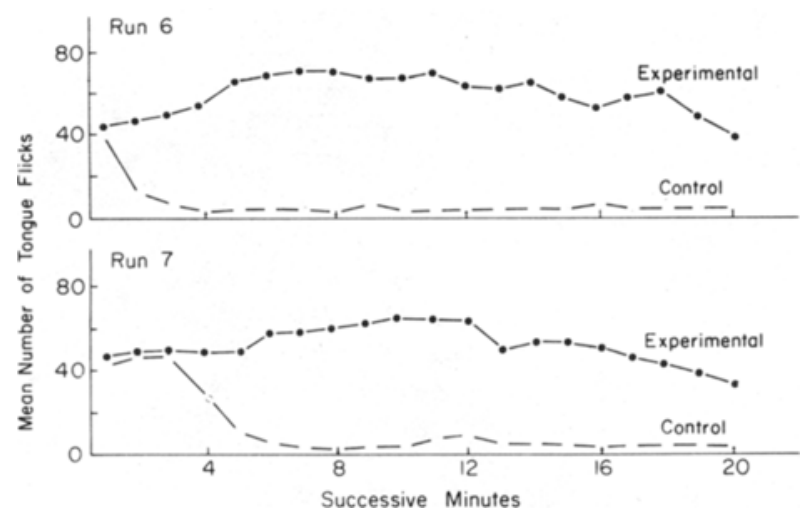

Figure 3. Mean number of tongue flicks per minute for $20 \mathrm{~min}$ after snakes were replaced into cleaned (experimental) or uncleaned (control) home cages. Results are shown separately for Runs 6 and 7.

\section{EXPERIMENT 3}

This experiment extends the above procedures to venomous snakes of the family Crotalidae. Some of the species used in Experiments 1 and 2 have been shown to be strongly dependent upon chemical cues in a variety of ways (feeding, reproduction, defense; see Burghardt, 1970, for a review). Moreover, recent evidence suggests that garter snakes and certain other species utilize conspecific odors selectively for aggregational purposes (Burghardt, 1977a; Dundee \& Miller, 1968; Porter \& Czapliki, 1974; Scudder, Stewart, \& Smith, 1980). Accordingly, it is not surprising that individuals of these species may use their own odors as marking cues. However, no data yet exist regarding chemical cue utilization by rattlesnakes during aggregation. Since chemical stimuli are known to be used by rattlesnakes during other behaviors, such as defense against predation and feeding (Bogert, 1941; Chiszar, Radcliffe, \& Scudder, 1977; Chiszar, Radcliffe, \& Smith, 1978; Chiszar, Scudder, Knight, \& Smith, 1978; Weldon \& Burghardt, 1979), it is not unreasonable to hypothesize that rattlesnakes will also have the ability to attend to their own odors and to use them as cues for orientational behaviors. The Goldberg (Note 1) study provided the only evidence that self-generated odors were attended to by rattlesnakes. Experiment 3 was designed to replicate Goldberg's results and to extend them to an additional taxon.

\section{Method}

The subjects were 12 rattlesnakes (6 Crotalus viridis and 6 C. durissus). All individuals were at least 3 years old, had been in captivity for at least 2 years, and had been living in their home cages for at least 6 months prior to the present study. The snakes were not experimentally naive; their previous experience involved exposure to a variety of prey odors but no surgical or pharmacological interventions. Accordingly, we believe these specimens to be typical of long-term captive crotalids. Maintenance conditions and experimental procedures were identical to those described for Experiment 2, with three exceptions: (1) Tongue flicks were recorded for $30 \mathrm{~min}$ after the snakes were reintroduced to their home cages; (2) a 5-h postreintroduction period was allowed as the maximum defecation latency (our experience with rattlesnakes is that the "clean-cage effect" on defecation requires more time than is the case with colubrids); and (3) the experimental and control treatments were manipulated within subjects. Three snakes of each taxon received the control treatment one week, followed a week later by the experimental treatment. The remaining three snakes of each taxon received the two treatments in the reverseorder.

\section{Results and Discussion}

In all statistical analyses that follow, the taxa were found to be virtually identical. In no case was there a significant main effect or interaction involving this factor (all ps $>.05$ ). Accordingly, data were pooled across taxa for presentation.

Mean latency to defecate was numerically shorter in the experimental than in the control condition ( 239 vs. $300 \mathrm{~min}$ ). In fact, none of the snakes defecated in the control condition during the 5-h observation period, whereas five $(\mathbf{4 2 \%})$ did so in the experimental condition $(\mathrm{p}=.031$ by one-tail sign test). Hence, we conclude that the "clean cage effect on defecation" occurred in these Crotalus specimens.

The tongue flick data are shown in Figure 4, where it can be seen that higher rates occurred in the experimental than in the control condition $[\mathrm{F}(1,11)$ $=6.82, \mathrm{p}<.05]$. Accordingly, it can be concluded that rattlesnakes responded to the absence of familiar odors in the clean home cage with greater investigatory behavior than can be attributed to handling and disturbance. 


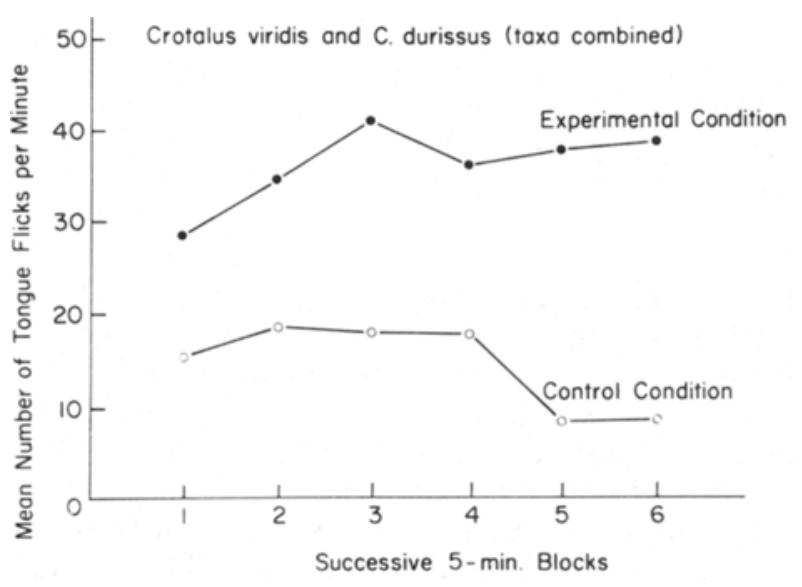

Figure 4. Mean number of tongue flicks per minute (plotted over six 5-min blocks) for 12 rattlesnakes that experienced both conditions during alternate weeks (Experiment 3). Six snakes were $C$. viridis and six were $C$. durissus. The taxon effect was insignificant; hence, data were pooled across taxa for presentation in this figure.

\section{EXPERIMENT 4}

Experiments 1-3 indicate that a clean cage induces defecation, whereas a soiled cage does not. However, it is not clear that fecal odors (or their absence) are the critical determinants of this phenomenon. For example, it could be that integumentary secretions (Bogert, 1941; Noble, 1937; Noble \& Clausen, 1936; Radcliffe \& Smith, 1977) rubbed onto objects in the soiled cage are the agents that suppress defecation. Experiment 4 was designed to show that odors associated with feces are at least partly responsible for the effects described in the previous experiments.

\section{Method}

Subjects and maintenance conditions were the same as those in Experiment 3. Each snake was exposed to four treatments. In all cases, the snake was removed from its home cage and placed in a holding pen while the home cage was thoroughly cleaned with warm water. In Condition $A$, the snake was then placed back into the clean home cage and all tongue flicks were recorded for the next $20 \mathrm{~min}$. Also, latency to defecate was recorded. In Condition B, a piece of paper smeared with feces from the snake's home cage was taped to the floor of the otherwise clean home cage. Feces were collected prior to cage cleaning; they were pulverized and rubbed on a clear floor cover. A $15 \times 15 \mathrm{~cm}$ piece of this paper was then taped to the floor covering of the clean home cage just prior to the replacement of the resident snake. In Condition $\mathrm{A}$, a clean paper insert was taped to the floor. In Condition $\mathrm{C}$, a paper insert containing fecal material from a conspecific was taped to the floor covering prior to replacing the snake. In Condition D, two paper inserts were applied to the floor, one containing fecal odors derived from the resident and the other containing fecal odors derived from a conspecific. These four conditions conform to a 2 by 2 orthogonal combination of presence vs. absence of odors derived from the cage resident's feces and the presence vs. absence of odors derived from a conspecific's feces.

It is possible that odoriferous chemicals of nonfecal origin (e.g., scent glands, integument) are sequestered in feces after the latter are deposited on the cage floor, and the present procedures for collecting and preparing feces probably do not eliminate such
}

contaminants. Accordingly, when we refer to "odors associated with feces," it must be understood that the active fraction may not be entirely of fecal origin. Nonetheless, feces are clearly the carriers of the odors under study here.

All snakes were exposed to all conditions (one condition per week), and all snakes were under 6 days of food deprivation at each test. Each snake experienced the four conditions in a randomly determined order (orders were independently selected for each snake).

\section{Results and Discussion}

Table 1 presents mean numbers of tongue flicks emitted by $C$. viridis and $C$. durissus in each of the four conditions. The main effect of species was insignificant, as were all interactions involving this factor. The condition (A) containing no fecal odors produced the highest frequency of tongue flicks in both species, whereas the remaining three conditions were characterized by far lower values. This pattern of results gave rise to a significant interaction between presence vs. absence of resident and conspecific fecal material $[F(1,10)=10.56, p<.01]$. Analysis of simple effects indicated that if fecal material of any sort was present, snakes of both species emitted significantly fewer tongue flicks than if feces were absent (see Table 1 for results of Duncan's multiple range test applied to all means). Snakes did not discriminate between their own fecal materials and those of a conspecific, indicating that the active chemical(s) may derive from effluents characteristic of the taxon (or a still higher level of classification).

Five instances of defecation occurred in Condition A, whereas only two instances occurred in all other conditions combined (one each in Conditions $\mathrm{B}$ and $\mathrm{D}$; $\mathrm{p}=.031$ by one-tail sign test). Accordingly, we conclude that odors associated with feces are causative with respect to suppression of tongue flicking and defecation, and that the clean-cage effects described in Experiments 1-3 are at least partially attributable to the absence of these odors.

\section{GENERAL DISCUSSION}

The experiments reported here make only the beginning of a case for fecal marking in colubrid, boid, and crotalid snakes. It is clear that cage cleaning in-

Table 1

Mean Number of Tongue Flicks Emitted by Six $C$. viridis (V) and Six $C$. durissus (D) During 20 Min of Exposure to Each of Four Conditions

Fecal Material Derived from Cage Resident

\begin{tabular}{cccccc}
\cline { 2 - 3 } $\begin{array}{c}\text { Fecal Material } \\
\text { Derived from } \\
\text { a Conspecific }\end{array}$ & \multicolumn{2}{c}{ Absent } & & \multicolumn{2}{c}{ Present } \\
\cline { 2 - 3 } \cline { 5 - 6 } & $\mathrm{V}$ & $\mathrm{D}$ & & $\mathrm{V}$ & $\mathrm{D}$ \\
\hline Absent & 721 & 672 & & $306^{*}$ & $197 \dagger$ \\
Present & $345^{*}$ & $209 \dagger$ & & $389^{*}$ & $329 \dagger$ \\
\hline
\end{tabular}

Note-SEM $=78$ for all means.

*Means do not differ significantly, but all differ from 721.

tMeans do not differ significantly, but all differ from 672 . 
duces defecation more frequently than a soiled cage. It is also clear that odors associated with feces are at least partly responsible for the suppression of defecation in the soiled cage. However, we are not certain about which of the chemicals are active or, for that matter, if the active chemicals are "acquired" by feces after deposition. Moreover, it is completely unknown whether odors associated with feces are used as marks by snakes under natural conditions, and it would be unwise to infer the existence of territoriality or home range in snakes on the basis of the present results (see Brown \& Parker, 1976; Fitch, 1958; Fitch \& Shirer, 1971, for criteria used in field studies of spatial relationships in snakes).

One important methodological point can be derived from these data: Snakes are likely to be in very different behavioral and physiological states, depending upon how soon after cage cleaning they are observed. In fact, too frequent cage cleaning may keep snakes constantly alert or otherwise "uncomfortable." Hence, excess variability might be introduced into behavioral experiments if this factor is left uncontrolled. A seemingly innocuous and even necessary part of laboratory routine may have to be watched closely in order that needless variation in animal attention, motivation, and excitation not be injected into or confounded with experimental treatments.

At the Philadelphia Zoo, it has been common practice to leave a few soiled items (stones, tree branches, etc) in snakes' cages after cleaning. This procedure has been followed because it results in less behavioral disturbance to the snakes than does a totally clean cage (Conant, 1971). The present data suggest that the effectiveness of this procedure derives from the snakes' sensitivity to self-generated odors and from their ability to induce a calming effect (i.e., such odors block the investigatory and defecatory consequences of cage cleaning).

Finally, it is necessary to consider the manner in which self-generated odors exert their effect on snakes. It may be that snakes are innately prepared to recognize these chemicals and to utilize them as navigational or aggregational cues (Burghardt, 1977a) and as boundary markers to alert others to (or to remind themselves of) their spatial occupation. It is also possible that individuals may learn to recognize their own odors, particularly under captive conditions in which few other odors compete for an individual's attention over long periods of time. Thus, cleaning a laboratory cage may produce a phenomenon akin to generalization decrement even in snakes that would not utilize their own odors as orienting marks in nature. These two hypotheses are not mutually exclusive, and each of them suggests appropriate followup studies (see Burghardt, 1977a, and Scudder, Stewart, \& Smith, 1980, for implications of the innate recognition hypothesis). The learning hypothesis considers all detectable odors to be potential familiarity cues. The reason that self-generated odors are utilized is that they are normally the only ones available to a captive snake maintained in an individual cage. Perhaps if other odors were incorporated into the cage, these too would become familiar to the animal such that their subsequent removal would give rise to a behavior pattern much like the clean-cage effect (even if self-generated odors remained in the cage). Preliminary results from studies ongoing in this laboratory indicate that this is exactly what happens. Although snakes may be innately prepared to recognize certain pheromones, they also appear to be able to learn to recognize a variety of other substances (e.g., formaldehyde, perfume) or at least to detect their absence from an environment that has long contained them. Many experiments on snake learning ability have used visual, spatial, or tactile cues as classical CSs or as operant discriminanda with mixed results (see Burghardt, 1977b, for a review). Perhaps very different outcomes would occur with chemical cues as conditioned and/or discriminative stimuli.

\section{REFERENCE NOTES}

1. Goldberg, J. Unpublished data, 1978.

2. Chiszar, D., Wellborn, S., \& Wand, M. A. The zoo keeper's dilemma: Cage cleaning and the induction of "marking" behavior by snakes. Presented at the meeting of the Animal Behavior Society, Seattle, 1978.

\section{REFERENCES}

Boge RT, C. M. Sensory cues used by rattlesnakes in their recognition of ophidian enemies. Annals of the New York Academy of Science, 1941, 41, 329-344.

Brown, W. S., \& Parker, W. S. Movement ecology of Coluber constrictor near communal hibernacula. Copeia, 1976, 225242.

Burghardt, G. M. Chemical-cue preferences in inexperienced snakes: Comparative aspects. Science, $1967,157,718-721$.

Burghardt, G. M. Comparative prey-attack studies in newborn snakes of the genus Thamnophis. Behaviour, 1969, 33, 77-114.

Burghardt, G. M. Chemical perception in reptiles. In J. W. Johnston, Jr., D. G. Moulton, \& S. Turk (Eds.), Communication by chemical signals. New York: Appleton-Century-Crofts, 1970.

Burghardt, G. M. Chemical prey preference polymorphism in newborn garter snakes, Thamnophis sirtalis. Behaviour, 1975. 52, 202-225

Burghardt, G. M. Of iguanas and dinosaurs: Social behavior and communication in neonate reptiles. American Zoologist, 1977, 17, 177-190. (a)

Burghardt, G. M. Learning processes in reptiles. In C. Gans, \& E. W. Tinkle (Eds.), Biology of the reptilia (Vol. 7) Ecology and Behavior A. New York: Academic Press, 1977. (b)

Chiszar, D., Carter, T., Knight, L., Simonsen, L., \& Taylor, $\mathrm{S}$. Investigatory behavior in the plains garter snakes (Thamnophis radix) and several additional species. Animal Learning \& Behavior, 1976, 4, 273-278.

Chiszar, D., Lipetz, V., Scudder, K., \& Pasanello, E. Rate of tongue flicking by bull snakes (Pituophis melanoleucus) during exposure to food and non-food odors. Herperologica. in press.

Cinstar, D., RadocilffF, C. W., \& Scudder, K. M. Analysis 
of the behavioral sequence emitted by rattlesnakes during feeding episodes. 1. Striking and chemosensory searching. Behavioral Biology, 1977, 21, 418-425.

Chiszar, D., Radcliffe, C. W., \& Smith, H. M. Chemosensory searching for wounded prey by rattlesnakes is released by striking: A replication report. Herp Review, 1978, 9, 54-56.

Chiszar, D., Scudder, K., \& Knight, L. Rate of tongue flicking by garter snakes (Thamnophis radix haydeni) and rattlesnakes (Crotalus v. viridis, Sistrurus catenatus tergeminus, and $S$. $c$. edwardsi) during prolonged exposure to food odors. Behavioral Biology, 1976, 18, 273-283.

Chiszar, D., Scudder, K., Knight, L., \& Smith, H. M. Exploratory behavior in prairie rattlesnakes (Crotalus viridis) and water moccasins (Agkistrodon piscivorus). Psychological Record, 1978, 28, 363-368.

Chiszan, D., \& Simonsen, L. Investigatory behavior in a captive pine snake (Piluophis melanoleucus melanoleucus). The Colorado Herpetologist, 1976, 2, 1-5.

Cociran, W. G., \& Cox, G. M. Experimental designs. New York: Wiley, 1950.

Conant, R. Reptile and amphibian management practices at Philadelphia Zoo. International Zoo Yearbook, 1971, 11, 224-230.

Cowles, R. B., \& Phelan, R. L. Olfaction in rattlesnakes. Copeia, 1958, 77-83.

Dundee, H. A., \& Miller, M. C., III. Aggregative behavior and habitat conditioning by the prairie ringneck snake, Diadophis puncratus amyi. Tulane Studies in Zoology and Botany, 1968, $15,41-58$.

Glickman, S. E., \& Sroges, R. W. Curiosity in zoo animals. Behaviour, 1966, 24, 151-188.

Fiтch, H. S. Home ranges, territories, and seasonal movements of vertebrates of the Natural History Reservation. University of Kansas Publications of the Museum of Natural History, 1958. 11. 63-326.
Fitch, H. S., \& Shire R, H. W. A radiotelemetric study of spatial relationships in some common snakes. Copeia, 1971, 118 128.

Fox, M. W. Abnormal behavior in animals. Philadelphia: Saunders, 1968.

HeDiger, H. The psychology and behaviour of animals in zoos and circuses. New York: Dover, 1968.

Noble, G. K. The sense organs involved in the courtship of Storeria, thamnophis, and other snakes. Bulletin of the American Museum of Natural Historv, 1937, 73, 673-725.

Noble, G. K., \& Clausen, H. J. The aggregation behavior of Storeria dekayi and other snakes with especial reference to the sense organs involved. Ecological Monographs, 1936, 6, 269-316.

Ponter, R. H., \& Czaplicki, J. A. Response of water snakes (Natrix $r$, rhombifera) and garter snakes (Thamnophis sirtalis) to chemical cues. Animal Learning \& Behavior, 1974, 2, 129-132.

RADCliffe, C. W., \& Smith, M. Observations on courtship and other behaviors in captive crotalidae. Journal of the ColoradoWyoming Academy of Sciences, 1977, 9, 2.

Scudder, K. M., Stewart, N. J., \& Smith, H. M. Response of neonate water snakes (Nerodia sipedon sipedon) to conspecific chemical cues (Reptilia, Serpentes, Colubridae). Journal of Herpetologv, 1980, 14, 196-198.

TAYLOR, S. V. Stimulus control of lingual air sampling in garter snakes (Thamnophis $\mathrm{r}$. haydeni) and rattlesnakes (Crotalus $\mathrm{v}$. viridis and Sistrurus c. tergeminus). Unpublished doctoral dissertation, University of Colorado, Boulder, 1976.

Weldon, P. J., \& Burghardt, G. M. The ophiophage defensive response in crotaline snakes: Extension to new taxa. Journal of Chemical Ecology, 1979, 5, 141-151.

(Received for publication November 20, 1979: revision accepted May 1, 1980.) 